\title{
Sexualidades e Resistências: uma Etnografia sobre Mulheres Encarceradas no Sertão Pernambucano
}

\author{
Laerte de Paula Borges Santos ${ }^{1}$ \\ ${ }^{1}$ Universidade Federal de Pernambuco, PE, Brasil.
}

\author{
Luis Felipe Rios ${ }^{1}$ \\ ${ }^{1}$ Universidade Federal de Pernambuco, PE, Brasil.
}

\begin{abstract}
Resumo: O presente artigo tem o intento de apresentar os dados obtidos através de uma pesquisa realizada em uma cadeia feminina localizada no interior do sertão pernambucano. Ancorado em uma perspectiva etnográfica, o objetivo foi o de compreender como mulheres encarceradas localizam suas experiências afetivas e sexuais em meio aos procedimentos disciplinares que regulam suas vidas no cotidiano da prisão. Os dados foram coletados a partir de observações no contexto de investigação e de 12 entrevistas realizadas com as internas que ali estavam presas. As informações obtidas foram registradas em diários de campo, transcritas e submetidas a análises etnográficas. Os resultados encontrados apontam para modos heterogêneos de se vivenciar desejos, prazeres e corporalidades na realidade carcerária, materializadas através das visitas íntimas, da troca de cartas e mensagens, da constituição de relacionamentos entre as internas, dos novos arranjos familiares que ali se desenhavam. As sexualidades são, portanto, importantes fios de resistência aos efeitos mortificadores que o cárcere coloca sobre suas trajetórias de vida.
\end{abstract}

Palavras-chave: Sexualidades, Prisões, Resistência, Mulheres, Psicologia.

\section{Sexualities and Resistance: An Ethnography about Women Arrested in the Sertão}

\begin{abstract}
The present article aims to present the data obtained through a research carried out in a female prison located in the sertão of Pernambuco. Anchored in an ethnographic perspective, the goal was to understand how incarcerated women locate their affective and sexual experiences in face of disciplinary procedures that regulate their daily lives in prison. The informations were collected through observations in the context of the investigation and twelve (12) interviews with women who were in prison. The data obtained were recorded in field diaries, transcribed and submitted to ethnographic analysis. The results found point to heterogeneous ways of experiencing desires, pleasures and corporalities in prison reality, materialized through intimate visits, the exchange of letters and messages, the constitution of a relationship between the internal ones, the new family arrangements that are designed there. Sexualities are, therefore, important threads of resistance to the mortifying effects that the jail puts on these women's lives.
\end{abstract}

Keywords: Sexualities, Prison, Strength, Women, Psychology. 


\title{
Sexualidades y Resistencias: Una Etnografía sobre Mujeres Encarceladas en el Sertão
}

\begin{abstract}
Resumen: El presente artículo tiene el propósito de presentar los datos obtenidos a través de una investigación realizada en una prisión femenina ubicada en el interior del sertão pernambucano. Anclado en una perspectiva etnográfica, el objetivo fue el de comprender cómo mujeres encarceladas localizan sus experiencias afectivas y sexuales en medios a los procedimientos disciplinarios que regulan sus vidas en lo cotidiano de la prisión. Los datos fueron recolectados a partir de observaciones en el contexto de investigación y de doce (12) entrevistas realizadas con las internas que allí estaban presas. Las informaciones obtenidas fueron registradas en diarios de campo, transcritas y sometidas a análisis etnográfico. Los resultados encontrados apuntan a modos heterogéneos de vivenciar deseos, placeres y corporalidades en la realidad carcelaria, materializadas a través de las visitas íntimas, del intercambio de cartas y mensajes, de la constitución de relacionamientos entre las internas, de los nuevos arreglos familiares que allí se dibujaban. Las sexualidades son, por lo tanto, importantes hilos de resistencia a los efectos mortificadores que la cárcel pone sobre sus trayectorias de vida.
\end{abstract}

Palabras clave: Sexualidades, Prisiones, Resistencia, Mujeres, Psicología.

\section{Introdução}

Este trabalho tem o intento de refletir sobre os múltiplos e complexos modos de expressão de desejos, prazeres e corporalidades no cotidiano de uma cadeia pública feminina localizada no interior do estado pernambucano. A pretensão aqui é de produzir algumas costuras analíticas a partir dos dados obtidos com a nossa pesquisa de mestrado. Esse estudo está ancorado no seguinte problema de investigação: Como se dão os modos de expressão das sexualidades no cotidiano de uma instituição prisional feminina?

O estudo ocorreu no período de julho a dezembro de 2017, com o retorno do pesquisador responsável pela coleta dos dados àquela instituição. Trata-se de uma pesquisa etnográfica sobre a vida em cadeia, viabilizada a partir de procedimentos de observação-participante e do uso de entrevistas com mulheres que estavam presas em regime fechado e semiaberto naquela unidade prisional.

Esse ensaio está dividido de modo a retratar os diferentes cenários, roteiros e dinâmicas de expressão das sexualidades das interlocutoras que participaram desse estudo. No primeiro tópico analítico, procuramos tratar dos lugares de vulnerabilidade e de violência que se inscreveram e se articularam à constituição das suas carreiras sexuais, que segundo Heilborn, Cabral e Bozon (2006), se referem às dinâmicas diversas de aprendizagens e socializações das vivências afetivas e sexuais. Na segunda e terceira parte, procuramos nos ater aos heterogêneos e complexos modos de expressão das suas experiências afetivo-eróticas no dentro/fora do cenário prisional investigado.

\section{Psicologia, sexualidades e prisões: O cortiço como gambiarra de um sistema penal precário e seletivo}

Esse texto é, portanto, um resgate de memórias vividas no cortiço-prisão, uma pequena unidade prisional destinada às mulheres do sertão brasileiro. Tomando a sexualidade como um dos principais fios de análise, começamos a mergulhar no cotidiano daquela instituição-prisão, de modo a perceber como aquelas mulheres jogavam com seus afetos e desejos, ali "na fronteira entre o inóspito e o invisível, bem no meio das grades e trancas, onde as moradoras fazem casas em gaiolas" (Santos, 2018, p. 55).

Cortiço foi o nome dado por uma das internas para marcar toda "sorte" de abandonos e precariedades que se colocavam/colocam sobre as trajetórias de vida das mulheres que se deslocavam/deslocam na rotina inerte daquela e de outras instituições totais.

Goffman (2007), em "manicômios, prisões e conventos", define as instituições totais como lócus produtores de separação da vida de dentro com o mundo externo, espaços que operam como uma mistura de casa e instituição organizada, onde os 
presos são submetidos a distintas formas de mortificação do eu.

O cenário de um cortiço-prisão, improvisado no prédio de uma antiga delegacia de polícia civil, localizado no centro de uma grande cidade do sertão brasileiro, parece posicionar aquela unidade prisional enquanto uma gambiarra do sistema jurídico-penal.

A gambiarra é o aparato de uma engrenagem de poder que marca os modos de organização de uma instituição falha e precária (Foucault, 2005) que se destina a capturar e gerir seletivamente (Wacquant, 2008) vidas que ocupam lugares não hegemônicos no que diz respeito às intersecções de raça, gênero, classe, sexualidade e território (Brah, 2006; Crenshaw, 2002).

Segundo Foucault (2005), as prisões na época clássica passaram a se configurar como dispositivos estratégicos de adestramento e gestão utilitária dos corpos marcados pelas mudanças nas políticas de punição aos indivíduos tidos como criminosos. A noção de dispositivo aqui trazida diz respeito a uma rede complexa que articula práticas, discursos, saberes, indivíduos e instituições (Foucault, 2001). Entram em cena os efeitos de um poder disciplinar que colocou a operações do corpo no cerne de uma mecânica de esquadrinhamento, vigilância e controle (Foucault, 2005).

As prisões são "máquinas de abandono" (Diniz, 2015a), artefatos sociais de produção e reprodução das inúmeras desigualdades que se forjam no âmbito das nossas relações cotidianas. Trata-se da instituição simbólica e material de políticas de segregação dos sujeitos tidos como indesejados e que supostamente se apresentam como ameaças à vida social (Cortina, 2015; Foucault, 2005; Souza, 2009).

Wacquant (2008) destaca o lugar social que a prisão ocupa no que diz respeito à materialização de "políticas de criminalização da pobreza", ao se colocar como uma instituição que confina e exclui populações socialmente vulneráveis e estigmatizadas, como pobres, negros e imigrantes, sobretudo, em contextos neoliberais de produção econômica marcados pela desmantelamento da aparelhagem estatal, desqualificação e precarização das relações de trabalho, desemprego e confinamento das pessoas mais pobres nos guetos e periferias dos grandes centros urbanos.

Para o autor, "o encarceramento é apenas a manifestação paroxística da lógica da exclusão etnorracial da qual o gueto tem sido instrumento e pro- duto desde a sua origem histórica" (Wacquant, 2008, p. 13). Assim, ao tratarmos das prisões como lócus de apartação e confinamento de corpos socialmente marginalizados, torna-se de suma importância localizarmos a inscrição de diferentes marcadores de desigualdade que se colocam como multiplicadores dos lugares de vulnerabilidade, exclusão e opressão (Nogueira, 1993) de quem sobrevive e se desloca nos/pelos territórios das prisões.

A metáfora da intersecção, trazida por Crenshaw (2002), para marcar os entrecruzamentos de distintos eixos de poder e subordinação dos corpos e subjetividades, torna-se cara para uma compreensão dos efeitos capilares que as prisões materializam no mundo ocidental contemporâneo.

O cárcere tem operado como efeito-destino para vidas matáveis, nuas, sem vez e sem voz em contextos marcados por desigualdades visíveis e gritantes no que diz respeito aos campos de articulação social, econômica e política (Soares, Félix-Silva, \& Figueiró, 2014; Souza, 2009).

O retrato de uma cadeia improvisada para trancafiar mulheres pobres é mais uma das inúmeras ilustrações que escancaram a tragédia social que tem sido implantada pelas políticas massivas de encarceramento que tomam conta da constituição da realidade brasileira.

Os mais recentes números publicados pelo Levantamento Nacional de Informações Penitenciárias (Brasil, 2017) apontam mais uma vez para o crescimento da população prisional brasileira (que entre 2000 e 2016 aumentou 157\%, passando de 232,8 para 726,7 mil pessoas presas), além de demarcar quem são e como vivem as pessoas encarceradas nas prisões do país, uma massa formada, em sua grande maioria, por pessoas negras (60\%), solteiras (60\%), jovens (55\% das pessoas presas tinham idades entre 18 e 29 anos) e pouco escolarizadas (51\% possuem apenas o ensino fundamental incompleto) (Brasil, 2017).

No que concerne às mulheres encarceradas, percebe-se que no período de 2000 a 2016, a população prisional feminina teve uma taxa de crescimento de $656 \%$, saltando de 6,5 mil para 40,6 mil mulheres presas em instituições prisionais do país. Mulheres em sua maioria negras $(62 \%)$, jovens com idades entre 18 e 29 anos (50\%), solteiras (62\%), que possuem apenas o ensino fundamental incompleto (45\%), presas acusadas por tráfico de drogas (62\%) e sem condenação (45\%) (Brasil, 2018). 
Esses dados revelam a efetividade dos dispositivos jurídico-penais em punir um corpo social marcado por inúmeras vulnerabilidades e experiências de abandono. Sujeitos que habitam territórios constituídos pelos efeitos das desigualdades de raça, gênero e classe, da violência urbana, do racismo, da insegurança e da prisão (Souza, 2009).

Destarte, o entendimento do encarceramento massivo de mulheres no Brasil a partir da noção de feminização da pobreza torna-se politicamente estratégico, pois revela as imbricações que as assimetrias de gênero colocam sobre esses terrenos sociais marcados pelo caráter seletivo que orienta às aplicações das leis penais por parte dos dispositivos estatais (Cortina, 2015; Lago, 2014).

Tal noção, bastante cara para o campo de estudos feministas e de gênero, diz respeito à "constatação estatística e social de que a pobreza tem atingido de forma significativa as mulheres e orientado suas escolhas de vida" (Cortina, 2015, p. 767). Para muitas delas, mães solteiras e provedoras do lar, o envolvimento e a aproximação com as diferentes dinâmicas de organização do tráfico de drogas fazem parte dos movimentos de resistência às condições de pobreza e precariedade que tomam conta das suas realidades de vida (Lago, 2014; Cortina, 2015; Diuana, Ventura, Simas, Larouzé, Correa, 2016).

Compreender os modos pelos quais os sujeitos vivenciam suas experiências afetivas e sexuais é também falar relações das inscrições de raça, classe e gênero, que de modo complexo se articulam e configuram as "diferenças que modelam a sexualidade" (Weeks, 2000, p. 41) e outras dimensões da nossa subjetividade.

A sexualidade, em uma perspectiva foucaultiana, pode ser compreendida enquanto um dispositivo de poder-saber, que desde a modernidade passou a se configurar como um dos principais alvos de um regime de governo dos prazeres. As ciências sexuais passam a expiar os desejos e a normalizar corpos e vontades através de técnicas confessionais de produção de verdades (Foucault, 2007).

Nessa perspectiva, ao nos colocarmos sobre as vidas encarceradas para falarmos das suas experiências afetivas e sexuais, estamos localizando um importante fio de organização das relações sociais que se estabelecem no dentro e no entorno das prisões (Cordeiro, 2017; D’Angelo, 2017; Padovani, 2015). A sexualidade, sobretudo, em tempos de grandes con- turbações na esfera política, torna-se um dos principais alvos de jogos de tensões e debates sobre a vida social (Rubin, 2003).

A psicologia, enquanto um solo heterogêneo de produção de saberes e práticas, pode voltar seus esforços para a construção de movimentos de articulação coletiva e de luta, que fomentem à superação das lacunas históricas colocadas pelas suas diversas abordagens e teorias, que serviram como mote disparador para processos de exclusão, estigmatização e normalização das diferenças (Karam, 2011; Rose, 2011).

Os manicômios e as prisões foram e são bons exemplos desses cenários que historicamente cumpriram/cumprem a função de distanciar do convívio social indivíduos tidos e qualificados como "loucos", "perigosos" e/ou "criminosos". A psicologia, desde o século XVIII, forneceu ferramentas poderosas para os dispositivos de punição, ao construir tecnologias individualizantes que permitiram à inscrição da delinquência e da criminalidade (Karam, 2011; Rose, 2011).

Ao pensar no lugar dos saberes e práticas "psi" nas prisões, gostaríamos de retomar a uma cena vivenciada no cortiço-prisão, que reitera práticas de anulação, silenciamento e de negação de direitos. Em uma das suas falas corriqueiras, uma psicóloga da instituição disse para uma das internas a seguinte frase: "Cadeia não é motel, visita íntima não é direito, é presente do Estado".

$\mathrm{Na}$ tessitura das relações que nesses espaços se estabelecem, inúmeras situações de violências (físicas, morais e psicológicas) têm se configurado enquanto peças que movem os jogos de forças que dão corpo à engrenagem carcerária, violências essas que se pulverizam de modos diversos, explícitos, sutis ou disfarçados (D’Angelo, 2017).

Para Rauter (2007), as prisões são "máquinas mortíferas" que mesmo disseminando seus efeitos nos diversos terrenos sociais, também produzem resistências. A psicologia, não em termos homogêneos, mas aquelas abordagens psicológicas que voltam seus fazeres para o tensionamento das desigualdades e para a afirmação das diferenças, pode se configurar como um potente mecanismo de resistência ao cárcere e às práticas mortificadoras que nele são produzidos e materializados.

Para que isso aconteça, os psicólogos devem resistir à engrenagem mortificadora da prisão, despindo-se das amarras e formalidades que aprisionam as suas práticas profissionais, caminhando em dire- 
ção às práticas libertadoras, inventivas, que afirmem as potencialidades dos corpos que sobrevivem nesses cenários (Rauter, 2007).

\section{Método}

A etnografia foi o aporte metodológico que ancorou a condução dessa pesquisa. Esse enfoque de investigação busca a compreensão das diversas dinâmicas de constituição das sociedades, seus códigos, valores, normas, culturas, instituições e modos de organização (Da Matta, 1978; Geertz, 2004; Malinowski, 1978). Trata-se de uma prática interpretativa das culturas que consiste em "estabelecer relações, selecionar informantes, transcrever textos, levantar genealogias, mapear campos, manter um diário e assim por diante (Geertz, 2004, p. 4).

\section{Universo de investigação}

O cenário de realização da pesquisa foi uma cadeia pública feminina localizada no sertão pernambucano, em uma cidade que faz fronteira com um território conhecido nacionalmente como o "polígono da maconha", uma importante região de plantação e escoamento da produção de cannabis que tem abastecido inúmeras cidades do Nordeste e de outras regiões do Brasil (Fraga, 2015).

Essa cadeia tem uma população aproximada de 60 internas, presas em sua grande maioria por crime de tráfico de entorpecentes, enquadradas no artigo 33 da Lei $\mathrm{n}^{\circ} 11.343 / 06$, atual artefato regulatório que tipifica e criminaliza a produção e comercialização de drogas ilícitas no Brasil.

As internas ficavam dispostas nas doze celas que a unidade prisional possuía. O convívio era o território das presas "comuns", o berçário era o destino das grávidas, das lactantes e das enfermas e a "espera", era onde ficavam confinadas as recém-chegadas por um período de dez dias, sem banho de sol e tampouco visitas.

Durante os seis meses de pesquisa de campo, procuramos perceber como as mulheres sobrevivem nesses cenários de abandono, de que nos fala Diniz (2015a). A fotografia era a de um pátio tomado por grades, grafites e desenhos que tentavam colorir as paredes inertes daquela instituição. Mulheres posicionadas em pequenas rodas de conversa, fazendo as unhas, arrumando os cabelos, jogando com a vida possível de se viver por ali.
Roupas lavadas e estendidas entre as grades. Faxinas matinais. Presas indo e vindo da escola. Cenas comuns no cotidiano do cortiço, repleto de celas que as presas aprenderam a chamar de casas. Naquela cadeia, as pequenas atividades cotidianas têm o nome de corre ou correria, mesmo nome dado pela rede de organização do tráfico para os serviços de venda e distribuição de pequenas quantidades de drogas.

Fazer pesquisa em uma instituição tomada por olhos vigilantes demanda confiança (Diniz, 2015b). $\mathrm{Na}$ prisão, tal relação parece funcionar como uma abertura de portas que dá acesso à vida de dentro. Sentado no piso das celas ou no chão do pátio era possível perceber como muitas moradoras gostavam de contar suas histórias e de serem escutadas. Falavam dos amores, dos familiares, das angústias e sonhos em meio à dureza da vida em cadeia.

\section{Participantes}

Os dados reunidos através dessa pesquisa retratam alguns aspectos da vida de diferentes personagens que nos emprestaram suas histórias para que aqui pudéssemos contar. Além das conversas propiciadas nas celas e no pátio da unidade prisional, também foram realizadas doze entrevistas como forma de aprofundarmos os elementos obtidos (Goldenberg, 2004) e adquirirmos informações não captadas através dos procedimentos de observação-participante (Rios, 2012).

As mulheres que foram entrevistadas, em sua maioria, se autodeclararam como negras ou pardas, solteiras ou casadas, heterossexuais na maioria, jovens, mães, católicas, evangélicas ou que apenas acreditam em Deus, presas por tráfico, furto ou por homicídio. Na vida do fora, elas trabalhavam como agricultoras, babás, domésticas ou cabeleireiras. Muitas delas já viram a prisão de perto antes mesmo de terem chegado ao cortiço-prisão através do encarceramento de pessoas próximas aos seus convívios, como pais, irmãos, amigos, companheiros e/ou vizinhos.

\section{Procedimentos para coleta dos dados}

Para a coleta dos dados, utilizamos como ferramentas metodológicas a observação-participante (Becker,1997; Rios, 2012) dos roteiros (Gagnon, 2006) e cenários (Paiva, 2008) que se desvelavam no cotidiano do cortiço-prisão, além de termos realizado 
entrevistas semiestruturadas que foram norteadas por um questionário previamente construído, onde constavam perguntas abertas sobre as experiências afetivas e sexuais vivenciadas ao longo das suas trajetórias de vida.

As observações ocorreram no pátio, na entrada da unidade, na escola e nas salas administrativas daquela unidade prisional, buscando sempre perceber como a sexualidade tomava corpo no dentro e no entorno daquela instituição.

Segundo Rios (2012), os procedimentos de observação-participante são importantes formas de investigação científica, pois colocam o pesquisador como parte da realidade em que se está inserido, posicionando-o em contato direto com as diferentes dinâmicas de constituição dos contextos de pesquisa.

As informações colhidas foram anotadas em diários de campo, fontes estratégicas de registro daquilo que era vivido durante o processo de incursão aos lócus de pesquisa, possibilitando aos pesquisadores resgatar memórias preciosas para a tessitura das análises, descrições e interpretações dos resultados alcançados (Rios, 2012).

As entrevistas aconteceram na sala do setor psicossocial da instituição prisional e duraram em torno de trinta minutos. Inicialmente foram prestados os esclarecimentos em relação aos objetivos e procedimentos da pesquisa, para que em seguida fossem realizadas a leitura e assinatura do Termo de Consentimento Livre e Esclarecido (TCLE). Tanto a direção da unidade, quanto as participantes consentiram o registro das informações em gravador, o que foi fundamental para o processo de transcrição e construção das análises posteriores.

As construções analíticas caminharam na direção de compreendermos os fios que vão tecendo a dinâmica de organização da vida no dentro e no fora do cortiço-prisão, de modo a percebermos como as mulheres localizam seus desejos e prazeres em meio aos jogos de força que por ali se desvelam.

Assim, buscamos compreender a vida nativa e interpretar as redes relacionais, os fluxos, as hierarquias, as resistências, as formas de organização e de gestão da vida cotidiana que na prisão vão sendo produzidas e rearranjadas (Geertz, 2004). O exercício era o de tensionar os estranhamentos e familiaridades que se irrompiam sobre o processo de imersão ao contexto de pesquisa (Da Matta, 1978).

\section{Considerações éticas}

Este trabalho foi aprovado pelo Comitê de Ética em Pesquisa (CEP) da Universidade Federal de Pernambuco - UFPE (Parecer n 2.159.340/2017) e seguiu os aspectos preconizados pela Resolução n $466 / 2012$, do Conselho Nacional de Saúde (CNS), que regula as pesquisas envolvendo seres humanos, de modo a salvaguardar a autonomia dos participantes, a beneficência, o consentimento, o sigilo e a confidencialidade das informações colhidas a partir do processo de investigação científica.

Mais do que atender às exigências deontológicas, compreendemos a ética enquanto um processo que deve alicerçar a construção de todas as etapas da pesquisa (Borges, Barros, \& Leite, 2013), por conseguinte, procuramos desfazer os jogos de força que posicionam as mulheres encarceradas em posições de anulação e subalternidade, permitindo condições profícuas à garantia da autonomia das interlocutoras no que diz respeito ao consentimento das suas participações na pesquisa.

\section{Resultados e discussão}

\section{Carreiras sexuais, vulnerabilidades e violências}

Nesta seção começaremos a desenhar os modos pelos quais as sexualidades aparecem impressas no cotidiano do cortiço-prisão. Longe de esgotar suas possibilidades de expressão, a ideia é aqui abordar os principais elementos e situações trazidas pelas interlocutoras ao longo das suas narrativas.

Para contar um pouco de como tais experiências se localizavam ali dentro, precisamos antes tratar de vulnerabilidades que se inscreveram e se articularam às vivências afetivas e sexuais das mulheres que por ali sobrevivem. Marta, por exemplo, é personagem da vida real, mulher negra, pobre, dependente de clonazepam e fluoxetina. Falar da sua história é tratar de um corpo que definha no/a partir do cárcere.

Ter conhecimento da sua trajetória foi atentar para um emaranhado de opressões e violências, que se colocaram sobre a sua vida antes mesmo da sua chegada ao território de uma instituição prisional. Abandonada pelos pais biológicos, foi criada por uma mãe e um pai que a adotou, ou como dizemos no sertão brasileiro, por uma família de criação. 
Marta foi categórica ao nomear sua primeira relação sexual como uma experiência de estupro. Sobre esse momento, ela descreveu um pouco da cena em que dois homens violentaram seu corpo e sua intimidade e tiraram sua virgindade: "aos 14 anos eu fui estuprada, tive uma filha, através desse estupro eu engravidei, não teve como tirar, né?! Aí a menina nasceu".

Teve aquela filha, foi mãe aos 14 . Sua filha viveu até os sete anos de idade, até que por uma contingência da vida, adoeceu e faleceu. Pouco tempo depois, Marta conheceu o seu atual companheiro, até então preso na penitenciária masculina da cidade.

Marta também caiu, ou seja, foi presa, capturada na entrada da prisão masculina com 133 gramas de maconha escondida na vagina. Era moradora do cortiço há mais de quatro anos e não recebia visita de quem quer que seja.

Sebastiana é uma mulher parda, que pouco foi à escola, mãe de cinco filhos, devota de Santo Expedito, vivia com a renda do bolsa-família e dos "bicos" que fazia como diarista. Assim como Marta também passou por situações de abusos e violências sexuais que começaram desde a infância, quando tinha 13 anos de idade.

Ao falar da sua primeira experiência afetivo-sexual, ela constrói uma narrativa do momento em que foi levada para uma casa abandonada da cidade e obrigada a manter relações íntimas com um homem bem mais velho, que morava pelos arredores da sua casa: "Foi ali mesmo, debaixo de um pé de manga numa casa abandonada, eu me sentia agoniada, mandando ele parar. Ele dizia: 'não fique quieta, fique quieta, depois você vai é gostar, você vai ficar é querendo'".

Engravidou após ter sido violentada por diversas vezes, teve de se casar e viveu anos em um casamento marcado por agressões físicas, psicológicas e materiais. Denunciou o ex-companheiro, mas de nada adiantou. Pediu o divórcio, se separou e não recebeu "um real" sequer referente à pensão dos cinco filhos menores de idade.

Sebastiana teve um segundo companheiro, que depois de um tempo foi preso por ter quebrado a pulseira eletrônica e fugido enquanto estava em regime semiaberto. No presídio masculino, ela era visitante assídua, chegava às 7 horas da manhã e só saía às 16 da tarde. Foi na fila do presídio que recebeu de uma visitante a proposta para fazer o seu primeiro corre.
Presa há dois meses, aguardava a audiência para que a sua situação se definisse.

Duas mulheres presas na mesma instituição, ambas com carreiras sexuais marcadas por episódios de opressão e violência. Corpos tomados como objetos de uma lógica obliterada de subjugação dos desejos e vontades das mulheres. Há muito o que se falar de gênero ao tomarmos uma cadeia feminina como lócus de investigação (Diniz, 2015b; Lago, 2014). Cenas dos próximos capítulos.

Gênero aqui pode ser compreendido a partir da noção de performatividade, trazida por Butler (2003) para marcar processos de produção de subjetividades através da repetição estilizada de normativas sociais que regulam modos improvisados de expressão no "interior de uma estrutura altamente rígida (p. 59).

\section{Desejos e prazeres costurados no dentro e no fora do cortiço-prisão}

No tocante aos modos como as internas vivem seus desejos e prazeres no dentro do território do cortiço, foi possível perceber ao longo das suas narrativas, uma centralidade localizada em torno da visita íntima, que talvez se deva ao fato de ser esse um dos poucos momentos em que suas vivências afetivo-eróticas se tornam minimamente legitimadas.

Estamos longe de dizer que as visitas íntimas nas unidades prisionais femininas não estão atravessadas por inúmeras edificações morais. D’Angelo (2017) já nos alertava para tal realidade ao tratar, por exemplo, do fato de que as mulheres presas só puderam acessar o direito à visitação íntima em 2001, 17 anos após os homens.

Parecem entrar em cena diversos mecanismos de controle dos corpos das mulheres apenadas, utilizados como artifícios para torná-los úteis e dóceis ao ordenamento da instituição prisional (Bassani, 2013; D’Angelo, 2017; Foucault, 2005). Nesse prisma, a sexualidade nas prisões muitas vezes tem sido percebida não enquanto um direito que deve ser garantido e afirmado para as pessoas que por ali sobrevivem, mas como um objeto de barganha, "moeda de troca", uma forma de acalmar às tensões e instabilidades acionadas pela maquinaria prisional (D’Angelo, 2017).

O cortiço-prisão não dispunha de um espaço reservado para que as visitas íntimas acontecessem. As internas improvisavam, arranjavam privacidade como podiam e conseguiam ali dentro. Das 60 mulheres, apenas 12 recebiam visitação íntima. Durante 
esse momento, as demais moradoras se retiravam das celas e aguardavam no pátio o tempo de visita acabar. Um lençol escuro amarrado na grade cumpria a função de tamponar o campo de visão das internas que estavam do lado de fora.

Nas celas, muita gente e pouco espaço. Lá dentro haviam oito jegas, uma espécie de cama de concreto, onde se colocavam cortinas e colchões, fotografias, ventiladores, produtos de higiene, passagens bíblicas e páginas arrancadas das revistas. Enfeitadas como um quarto, davam ou tentavam trazer cor e vida ao pequeno cubículo onde as internas ficavam/ ficam confinadas.

Sandra é mais uma das muitas que ali estão presas por tráfico de drogas. Em uma conversa de pátio, ela conta um pouco sobre como é receber o seu companheiro ali dentro: "Domingo eu fui sentar em um banco, não aguentei porque 'tava' toda dolorida. Aquela cela ali quase cai, faço todo tipo de posição, é na frente, é atrás. Boto a perna no batente da jega, é no banheiro". As jegas pareciam operar como microcenários nos quais as experiências afetivo-sexuais se desvelavam na vida de dentro do cortiço-prisão.

Como eram poucas presas que recebiam visitação íntima na unidade, as internas não precisavam compartilhar a cela com outros casais no momento da visita, fato corriqueiro no presídio masculino e sobre o qual trataremos a seguir. Nas falas das mulheres entrevistadas, os trânsitos entre as unidades feminina e masculina apareciam como elementos recorrentes na vida de muitas internas que estavam ali fixadas.

Um desses movimentos diz respeito às visitas íntimas das mulheres presas no presídio masculino. Para que uma moradora do cortiço pudesse visitar os seus companheiros no território de lá, era necessária a realização de um cadastro junto ao setor psicossocial da penitenciária masculina e a solicitação de uma autorização judicial que permitisse o deslocamento da interna em direção à outra unidade prisional, que só acontecia mediante escolta dos agentes penitenciários. Quinzenalmente, cinco ou seis mulheres eram levadas em uma viatura do sistema penitenciário do estado, todas elas algemadas pelos braços.

O que também despertava a nossa atenção era o fato de que o trânsito dos homens em direção à unidade prisional feminina não acontecia e não fazia parte dos modos de operacionalização das visitas. Ao nos colocarmos diante do cárcere, vamos percebendo que a linguagem, os códigos, os modus ope- randi das prisões parecem funcionar a partir de uma lógica hegemonicamente masculina (Cordeiro, 2017; Diniz, 2015b).

Alguns desses relacionamentos eram anteriores às suas prisões, outros, no entanto, tramados ali mesmo através dos "vasos comunicantes", artefatos (celulares, mensagens, cartas, recados) que conectavam as moradoras de dentro com outras pessoas que vivem no extramuros do cortiço-prisão (Godoi, 2010). As internas trocavam mensagens de texto ou enviavam cartas e fotografias através dos agentes penitenciários ou das demais presas que já transitavam pela unidade masculina.

Rosana, por exemplo, foi presa há dois anos com 100 gramas de maconha em uma rua próxima de sua casa, vivia sozinha no cortiço-prisão quando por intermédio de uma companheira de cela, decidiu tentar arranjar um namorado no presídio destinado aos homens. Mandava cartas e fotos para ele, até que conseguiu uma autorização para visita-lo. Autorização essa que costuma demorar em torno de três meses para ser expedida.

Ela lembrava desse dia em uma das muitas conversas ditas durante o banho de sol e trazia a seguinte descrição: "Saí daqui 'pra' encontrar o cara na penitenciária, pense 'num' cara feio da peste! Não tinha visto ainda não, só na foto. Chegou lá, ele me deu cachaça, só me comeu porque eu 'tava' bêbada".

Nessas redes relacionais, as internas vão tramando afetos e prazeres no cotidiano da reclusão (Padovani, 2015). Sobre esses modos de comunicação, Josefa, presa em um presídio masculino com 50 gramas de maconha e 100 gramas de cocaína na vagina, nos traz o seguinte relato: "Foi por meio de carta, como as meninas fazem. Depois da carta, eu fui fazer o cadastro. Eu consegui o número dele e a gente ficava conversando, quando foi no domingo eu fui visitar ele, toda iludida".

Esses fluxos de interação entre o dentro e o fora das prisões compõem aquilo que D’Angelo (2017) localiza enquanto movimentos de recriação da vida, forjados como forma de sobrevivência aos efeitos capilares dessas instituições que voltam seus procedimentos para anulação das vidas que ali estão posicionadas (D’Angelo, 2017).

$\mathrm{Na}$ unidade prisional masculina havia uma grande quantidade de mulheres ("presas" e "não presas") que visitavam seus companheiros. Nos retratos obtidos a partir das conversas cotidianas e das entre- 
vistas, ficava explícito o fato de que as mulheres visitantes precisavam compartilhar a mesma cela com outros casais durante o momento de visita íntima, como nos conta Josefa: "A diferença que eu percebo é que aqui (na cadeia feminina), os casais ficam só na cela, tiram visita sem mais ninguém. Presídio grande quem quiser que se ajeite com vários casais na cela, todo mundo embolado".

Para conferir algum tipo de privacidade ao encontro afetivo-sexual era, e talvez ainda seja, preciso lançar mão de algumas estratégias. Sebastiana que continuou a visitar o seu companheiro depois que foi presa, nos traz uma fala que ilustra um pouco dos modos de funcionamento e das dinâmicas de organização desses cenários, bem como nos aponta para o fato de que na realidade da tranca, os presos precisam produzir novos arranjos das condições internamente compartilhadas dentro das celas:

Lá tem tipo essa cama, com a outra em cima, tem outra cama com outra em cima e tem essa, cada cama daquela eles "arrodea" de pano. Eles "faz" tipo uns varais, manda furar com a furadeira no chão, coloca aquele gancho "pra" amarrar o cordão por dentro, pronto, coloca aquelas cortinas, cada um fica com seu espacinho, do quadradinho, bem pequeninho, só dá mesmo pra duas pessoas ficar, pra ninguém escutar a zoada de nada, cada um liga um som, liga uma televisão, um DVD bem alto (Sebastiana).

\section{Vivências homoeróticas no território de dentro: Desejos, prazeres e possibilidades de sobrevivência}

Ao longo das entrevistas, pudemos perceber que no jogo das possibilidades de expressão das sexualidades encarceradas, as vivências homoeróticas também apareceram como um dos fios que costura os processos de resistência às inúmeras dinâmicas de produção de solidão e abandono que ali dentro se materializam.

Severina é uma das presas com maior sentença no território do cortiço, 42 anos é a sua pena, presa sob a acusação de latrocínio e sem previsão de saída. Nessa e em outras unidades prisionais por onde esteve, ela aprendeu a reinventar seus desejos e corporalidades, lançando mão de múltiplas estratégias que lhe permitiram sobreviver, mesmo em um espaço de silenciamento, como destaca a partir do seguinte relato:

Fiquei um bom tempo sozinha, porque eu fui presa e fiquei em outro presídio. Lá eu comecei a sentir desejo por mulher, eu pensava "quero namorar essa menina!" Não, eu "tô" é louca! Vou tirar isso da mente, vou é procurar um homem [...] depois eu mesmo fui até ela e pedi um beijo. Hoje eu acho que a gente tem que viver o que gosta e o que quer, entendeu? (Severina).

As experimentações homoeróticas embora recorrentes no imaginário construído em torno da vida das mulheres que vivem em situação de prisão, não apresentam apenas uma possibilidade de expressão e tampouco se reduzem a lógicas matizadas por explicações essencialistas e estigmatizantes (Barcinski, 2012; Cordeiro, 2017; D' Angelo, 2017; Padovani, 2015).

Severina teve algumas namoradas ali dentro, mesmo quando estava de castigo e era impossibilitada de ter seu encontro íntimo, conseguia desenvolver formas de contornar às malhas de poder tecidas pela instituição e localizar seus desejos e vontades no cotidiano da tranca, como nos aponta na seguinte passagem: "Eu dava meu jeito, era muito danada, eu fazia com ela mesmo, fazia "pra" que ninguém percebesse, entende? Porque lá era muito lotado, então ninguém ia ficar prestando atenção. A gente dava uns truquezinhos".

Assim como Barcinski (2012), procuramos romper as restrições colocadas pelos que acionam os binarismos do sistema de sexo/afeto para compreender como se postam as vidas encarceradas. Esse binômio, segundo a autora, diz respeito ao entendimento que reduz as experiências afetivo-sexuais das mulheres no cárcere à necessidade de suprir suas condições de solidão e carência, sem recorrer, no entanto, aos jogos de força e às relações de poder que materializam assimetrias nas relações ali costuradas.

Ao localizarmos os diversos relacionamentos que se tecem entre as próprias internas, precisamos falar do caráter produtivo que a sexualidade coloca sobre os corpos e subjetividades que se constituem a partir dos efeitos balizados pelo cárcere. Através desse fio de produção de vida, temos a tessitura de uma rede que posiciona modos heterogêneos de ser e estar na tranca, na qual afetos, desejos e prazeres se arranjam 
e driblam as tentativas de apagamentos que nesses cenários se expressam incessantemente (D’Angelo, 2017; Padovani, 2015):

Era assim, por exemplo, até na hora da visita, a gente botava um colchão no chão, eu colocava uma calça de tecido mole, saía sem calcinha, e aí a gente ficava, que dá "pra" namorar aqui dentro dá, quando a gente quer não dificulta não, mas claro que é não é da forma que eu quero e desejo (Severina).

A prisão ao passo que fragiliza potências e singularidades, também vai produzindo resistência. Um exemplo dos elos de resistência que por ali se desvela está na constituição de novas relações familiares. Famílias que se arranjam através dos encontros amorosos e sexuais, das amizades, do afeto e da ajuda mútua acionados pelas trocas de alimentos, de conversas, de dinheiro e pela possibilidade de compartilhamento dos sonhos e tensões ali forjados (Padovani, 2015), como nos aponta Severina ao falar da atual companheira: "Eu e ela não tínhamos visita de ninguém, viramos uma a família da outra aqui dentro".

A vida na reclusão pede resistência. Na realidade da tranca e da grade, "sobrevivência é arma de ponta afiada” (Santos, 2018, p. 18). As mulheres jogam com os seus corpos e afetos, lançando mão dos artifícios disponíveis para produzir vida nesses cenários que tentam mortificar suas subjetividades (Goffman, 2007; Rauter, 2007).

\section{Considerações finais}

Essa pesquisa buscou mostrar uma espécie de fotografia das possibilidades de expressão das sexualidades em uma unidade prisional feminina. Para tanto, foi preciso acionar outros marcadores de desigualdade (raça, classe, gênero e sexualidade) que constituem processos de abandono e posicionam mulheres e homens, negros, pobres e periféricos em territórios vulneráveis aos efeitos do racismo, da violência e do encarceramento em massa, que se configura como uma política de gestão das condições de pobreza e das desigualdades socioculturalmente produzidas.

$\mathrm{O}$ intento aqui foi o de fazer um recorte para falar de como as mulheres localizam suas experiências afetivo-eróticas nas prisões. Trazer as sexualidades encarceradas como objetos de investigação é falar dos trânsitos e fronteiras, dos jogos de força, das redes relacionais e institucionais que no/a partir do encarceramento são produzidas e/ou reconfiguradas.

Os resultados encontrados apontam para modos heterogêneos de se vivenciar desejos, prazeres e corporalidades na realidade carcerária, materializadas através das visitas íntimas, da troca de cartas e mensagens, da constituição de relacionamento entre as internas, dos novos arranjos familiares que ali vão sendo desenhados. Tratar das sexualidades na prisão é localizar processos de produção de vida e de resistência aos efeitos de poder que o cárcere coloca sobre os corpos que por ali se deslocam.

O cortiço-prisão conta a vida de mulheres de um sertão resistente. Mulheres, que mesmo envoltas na realidade das trancas e grades materializadas por uma instituição total, criam formas de vivenciar seus prazeres e corporalidades e de experimentar modos possíveis de sobrevivência aos contextos que determinam quem tem ou não direito à vida.

Ao pensarmos na psicologia como um dispositivo de luta e de transformação das realidades sociais, precisamos alinhavar nossos discursos e práticas na direção de um projeto ético-político que tensione as políticas massivas de encarceramento no Brasil. Precisamos nos aproximar dos corpos que sobrevivem nos guetos, nos sertões, nas periferias e nas prisões, tornar o cuidado e o acolhimento como elementos disparadores das nossas práticas, lutar por saúde e melhoria na qualidade de vida das pessoas que transitam ou que ocupam os territórios das prisões.

Nossas práticas de cuidado não podem estar amordaçadas aos limites colocados pelos fazeres estritamente técnicos, burocráticos, alienantes e desconectados das realidades que se colocam sobre os nossos horizontes de atuação. E para nos descolarmos das amarras que se interpõem sobre os nossos caminhos profissionais, torna-se extremamente importante que estejamos comprometidos com os sujeitos e com a transformação das múltiplas desigualdades que na prisão se intersectam.

Precisamos alinhar os saberes "psi" aos movimentos de articulação política e de resistência à prisão, bem como materializar ações que caminhem para o tensionamento e implosão dos dispositivos que produzem/reproduzem violência, encarceramento e genocídio dos corpos marcados como subalternos e desimportantes. 


\section{Referências}

Barcinski, M. (2012). Expressões da homossexualidade feminina no encarceramento: O significado de se "transformar em homem” na prisão. Psico-USF, 17(3), 437-446. https://doi.org/10.1590/S1413-82712012000300010

Bassani, F. (2013). Visita íntima: O gerenciamento da sexualidade nas prisões do Brasil (dissertação de mestrado). Universidade Federal do Rio Grande do Sul, Porto Alegre, RS, Brasil.

Becker, H. (1997). Problemas de inferência e prova na observação participante. In: H. Becker, Métodos de pesquisa em ciências sociais (pp. 47-64). São Paulo: Hucitec.

Borges, L. O., Barros, S. C., \& Leite, C. P. R. L. A. (2013). Ética na pesquisa em Psicologia: princípios, aplicações e contradições normativas. Psicologia: Ciência e Profissão, 33(1), 146-161. https://doi.org/10.1590/S141498932013000100012

Brah, A. (2006). Diferença, diversidade, diferenciação. Cadernos Pagu, (26), 329-376. https://doi.org/10.1590/ S0104-83332006000100014

Brasil. Ministério da Justiça. Departamento Penitenciário Nacional. (2017). Levantamento nacional de informações penitenciárias. Brasília, DF: o autor.

Brasil. Ministério da Justiça. Departamento Penitenciário Nacional. (2018). Levantamento nacional de informações penitenciárias: Infopen mulheres. Brasília, DF: o autor.

Butler, J. (2003). Problemas de gênero: Feminismo e subversão da identidade. Rio de Janeiro, RJ: Civilização Brasileira.

Cordeiro, F. (2017). Criminalidade, gênero e sexualidade em uma penitenciária para mulheres no Brasil. Trivium: Estudos Interdisciplinares, 9(1), 1-15. http://dx.doi.org/10.18379/2176-4891.2017v1p.1

Cortina, M. O. C. (2015). Mulheres e tráfico de drogas: Aprisionamento e criminologia feminista. Revista Estudos Feministas, 23(3), 761-778. https://doi.org/10.1590/0104-026X2015v23n3p761

Crenshaw, K. (2002). Documento para o encontro de especialistas em aspectos da discriminação racial relativos ao gênero. Revista Estudos Feministas, 10(1),171-188. https://doi.org/10.1590/S0104-026X2002000100011

Da Matta, R. (1978). O ofício do etnólogo, ou como ter 'anthroopological blues'. In: Nunes, E. (Org). A aventura sociológica (pp. 23-35). Rio de Janeiro, RJ: Zahar.

D’Angelo, L. B. (2017). Entre "sujeita-mulher" e "mulher de bandido": Produção de feminilidades em contexto de privação de liberdade (dissertação de mestrado). Universidade do Estado do Rio de Janeiro, Rio de Janeiro, RJ, Brasil.

Diniz, D. (2015a). Cadeia de papel: Escrevo, por quê e para quem? Revista Liberdades, 19, 104-109.

Diniz, D. (2015b). Pesquisas em cadeia. Revista Direito GV, 11(2), 573-586. https:// doi.org/ 10.1590/1808-2432201525

Diuana, V., Ventura, M., Simas, L., Larouzé, B., \& Correa, M. (2016). Direitos reprodutivos das mulheres no sistema penitenciário: tensões e desafios na transformação da realidade. Ciência \& Saúde Coletiva, 21(7), 20412050. https:// doi.org/10.1590/1413-81232015217.21632015

Foucault, M. (2001). Ditos e escritos: Estética: Literatura e pintura, música e cinema (Vol. 3). Rio de Janeiro, RJ: Forense Universitária.

Foucault, M. (2007). História da sexualidade: Vontade de saber (16a ed.). Rio de Janeiro, RJ: Graal.

Foucault, M. (2005). Vigiar e punir: História da violência nas prisões (30a ed.). Petrópolis, RJ: Vozes.

Fraga, P. C. P. (2015). A participação feminina no plantio de cannabis no Vale do São Francisco. In: P. C. P. Fraga (Org.), Mulheres e criminalidade. Rio de Janeiro, RJ: Letra Capital.

Gagnon, J. (2006). Uma interpretação do desejo: Ensaios sobre o estudo da sexualidade. Rio de Janeiro, RJ: Garamond.

Geertz, C. (2004). A interpretação das culturas. Rio de Janeiro, RJ: Zahar.

Godoi, R. (2010). Ao redor e através da prisão: cartografias do dispositivo carcerário contemporâneo (dissertação de mestrado). Universidade de São Paulo, São Paulo, SP, Brasil.

Goffman, E. (2007). Manicômios, prisões e conventos (7a ed.). São Paulo, SP: Perspectiva.

Goldenberg, M. (2004). A arte de pesquisar: Como fazer pesquisa qualitativa em Ciências Sociais (8a ed). Rio de Janeiro, RJ: Record. 
Heilborn, M. L., Cabral, C. S., \& Bozon, M. (2006). Valores sobre sexualidade e elenco de práticas: Tensões entre modernização diferencial e lógicas tradicionais. In: M. L. Heilborn, E. M. L. Aquino, M. Bozon, D. R. Knauth (Orgs.), O aprendizado da sexualidade: Reprodução e trajetórias sociais de jovens (pp. 212-265). Rio de Janeiro, RJ: Garamond.

Karam, M. L. (2011). Psicologia e sistema prisional. Revista EPOS, 2(2).

Lago, N. B. (2014). Mulheres na prisão: Entre famílias, batalhas e a vida normal (dissertação de mestrado). Universidade de São Paulo, São Paulo, SP, Brasil.

Lei No 11.343, de 23 de agosto de 2006. Prescreve medidas para prevenção do uso indevido, atenção e reinserção social de usuários e dependentes de drogas; estabelece normas para repressão à produção não autorizada e ao tráfico ilícito de drogas; define crimes e dá outras providências. Diário Oficial da União, 24 ago. 2006.

Malinowski, B. (1978). Os argonautas do pacífico Ocidental: Um relato do empreendimento e da aventura dos nativos nos arquipélagos da Nova Guiné melanésia (2a ed.). São Paulo, SP: Abril Cultural.

Nogueira, C. (1993). Introdução à teoria da interseccionalidade nos estudos de gênero. In: S. Neves (Org.), Gênero e ciências sociais (pp. 67-78). Porto: Edições ISMAI.

Padovani, N. C. (2015). Sobre casos e casamentos: Afetos e "amores" através de penitenciárias femininas em São Paulo e Barcelona (tese de doutorado). Universidade Estadual de Campinas, Campinas, SP, Brasil.

Paiva, V. (2008). A psicologia redescobrirá a sexualidade?. Psicologia em Estudo, 13(4), 641-651. https://doi. org/10.1590/S1413-73722008000400002

Rauter, C. (2007). Clínica e estratégias de resistência: Perspectivas para o trabalho do psicólogo em prisões. Psicologia \& Sociedade, 19(2), 42-47. https:/ / doi.org/10.1590/S0102-71822007000200006

Rios, L. F. (2012). Fara Logun: A pesquisa formativa e a Implementação de um projeto de prevenção para homens jovens com práticas homossexuais no candomblé. In: L. Puppo, F. Seffner, \& V. Paiva (Orgs.). Vulnerabilidade e direitos humanos. Curitiba, PR: Juruá.

Rose, N. (2011) Inventando nossos selfs: Psicologia, poder e subjetividade. Petrópolis, RJ: Vozes.

Rubin, G. (1993). O tráfico de mulheres: Notas sobre a "economia política" do sexo. Recife, PE: SOS Corpo.

Santos, L. P. B. (2018). Sexualidades encarceradas: Afetos, desejos e prazeres no cotidiano do cortiço-prisão feminino do interior pernambucano (dissertação de mestrado). Universidade Federal de Pernambuco, Recife, PE, Brasil.

Soares, G. P., Félix-Silva, A. V., \& Figueiró, M. E. S. S. (2014). Teatro-menor: Cartografia em arte e experimentação de mulheres em situação de cárcere. Psicologia \& Sociedade, 26(spe), 89-99. https:// doi.org/10.1590/S010271822014000500010

Souza, J. (2009). Ralé brasileira: Quem é e como vive. Belo Horizonte, MG: Editora UFMG.

Wacquant, L. (2008). O lugar da prisão na nova administração da pobreza. Novos Estudos CEBRAP, (80), 9-19. https:// doi.org/10.1590/S0101-33002008000100002

Weeks, J. (2000). O corpo e a sexualidade. In: G. L. Louro (Org.). O corpo educado: pedagogias da sexualidade (2a ed., T. T. Silva, trad.). Belo Horizonte, MG: Autêntica.

\section{Laerte de Paula Borges Santos}

Doutorando e Mestre em Psicologia pela Universidade Federal de Pernambuco (UFPE). Recife - PE. Brasil. Graduado em Psicologia pela Universidade Federal do Vale do São Francisco (UNIVASF). Pesquisador vinculado ao Laboratório de Estudos da Sexualidade Humana (Labeshu/UFPE).

E-mail: laertedepaula13@gmail.com

(iD https:// orcid.org/0000-0002-1256-7931

Luis Felipe Rios

Professor do Programa de Pós-Graduação em Psicologia (PPG-Psi) da Universidade Federal de Pernambuco (UFPE), Recife - PE. Brasil. Doutor em Saúde Coletiva pela Universidade do Estado do Rio de Janeiro (UERJ), Rio de Janeiro - RJ. Brasil.

E-mail: lfelipe.rios@gmail.com

(iD) https:// orcid.org/0000-0002-0767-7845 
Endereço para envio de correspondência:

Universidade Federal de Pernambuco, Centro de Filosofia e Ciências Humanas, Programa de Pós-Graduação em Psicologia. Avenida Professor Moraes Rego, 1235, Cidade Universitária, Recife - PE, CEP: 50.670-901.

Recebido 19/08/2018

Aprovado 24/08/2018

Received 08/19/2018

Approved 08/24/2018

Recibido 19/08/2018

Aceptado 24/08/2018

Como citar: Santos, L. P. B., \& Rios, L. F. (2018). Sexualidades e resistências: Uma etnografia sobre mulheres encarceradas no Sertão. Psicologia: Ciência e Profissão, 38(n.spe.2), 60-72.

https://doi.org/10.1590/1982-3703000212379

How to cite: Santos, L. P. B., \& Rios, L. F. (2018). Sexualities and resistance: An ethnography about women arrested in the Sertão. Psicologia: Ciência e Profissão, 38(n.spe.2), 60-72. https://doi.org/10.1590/1982-3703000212379

Cómo citar: Santos, L. P. B., \& Rios, L. F. (2018). Sexualidades y resistencias: Una etnografía sobre mujeres encarceladas en el Sertão. Psicologia: Ciência e Profissão, 38(n.spe.2), 60-72. https://doi.org/10.1590/1982-3703000212379 